\title{
Role of narrative-based medicine in proper patient assessment
}

\author{
Giovanni Rosti ${ }^{1}$
}

Received: 5 October 2016/Accepted: 27 December 2016/Published online: 21 February 2017

(C) The Author(s) 2017. This article is published with open access at Springerlink.com

\begin{abstract}
Improving patient-physician communication is an area of medicine that deserves greater attention. Narrative medicine can be considered as one tool that can aid in fostering better communication. Current medical practice is dominated by evidence-based medicine, and dictates what therapies the clinician will offer in a given circumstance, ideally supported by (evidence-based) guidelines. However, when taken alone it tends to decentralize the patient. There are many different approaches that can be used to understand the patient and what he or she is experiencing as a result of their illness. While time constraints are often mentioned as a barrier to improved communication, in reality the time required to listen to patients is not excessive, and all caregivers should reflect on the possibility to give patients greater freedom from time constraints during consultation, and encourage them to narrate their experiences. Moreover, use of narrative-based medicine may be associated with better diagnosis and treatment of pain. Narrative-based medicine is not just for end-of-life care, but something for all caregivers to give greater consideration to in daily practice in order to form a strong frame of alliance.
\end{abstract}

Keywords Cancer $\cdot$ Narrative-based medicine .

Patient-physician communication · Diagnosis · Treatment .

End-of-life

Improving patient-physician communication is an often overlooked area of medicine. However, it is certainly one that deserves greater attention due to the complexity of the patient

Giovanni Rosti

rosti.giovanni@gmail.com

1 Oncology, Policlinico San Matteo IRCCS, Pavia, Italy journey that includes multimodality therapies, side effects, and especially, the prognostic outlook of cancer.

Patients may have difficulty in communicating to physicians, and in turn, physicians may also have difficulty, for many reasons, to properly assess patient's needs. Consider, for example, a retired man with metastatic prostate cancer who when asked by his physician rates his pain as 3 . For the physician, this would be considered mild pain, and therapy would be continued with no changes. However, the physician could, for example, query the man about the impact that this mild pain has on his quality of life. Being retired, he might say that even if the pain is mild, he is no longer able to carry out daily activities that he would otherwise have a strong desire to continue. He used to be able to help his son out at the hardware store moving boxes and staying at the cash register, talking with old friends. With his mild pain, he no longer feels up to this, and so he must stay at home. Obviously, this has a large impact on his social and daily life. Better communication with patients, and trying to understand the individual issues that affect them, and how they perceive and deal with even mild pain, as in this case, could help the physician to understand that a pain score of 3 may be considered as a relative score that actually merits better treatment. In such a context, better communication through narrative medicine can have a beneficial effect on the patient's overall quality of life.

\section{The definition of narrative medicine}

Narrative medicine can be considered as a medical educational tool that is informed by reading, writing, telling, and receiving stories. It invites one to be moved by the story of illness, and promotes a healing relationship with patients, colleagues, and the self. The concept of narrative medicine was first established by Dr. Rita Charon. In her opinion, narrative 
medicine is a model for empathy, reflection, profession, and trust, and was proposed as a "model for humane and effective medical practice" [1]. Furthermore, narrative medicine fortifies "clinical practice with the narrative competence to recognize, absorb, metabolize, interpret, and be moved by the stories of illness" [2]. Narrative medicine has been studied as a means of training medical students and enhancing developing clinical skills [3]. Training in narrative medicine was found to develop and improve specific communication skills, enhance the capacity to collaborate, empathize, adopt a patient-centered approach, and help physicians to develop personally and professionally through reflection. Thus, narrative medicine can have several benefits that may help improve daily practice and achieve narrative competence (Fig. 1).

\section{Narrative vs. evidence-based medicine}

Current medical practice is dominated by evidence-based medicine, or that supported by a variety of clinical evidence, the highest being meta-analyses and randomized, controlled, and blinded clinical trials. Evidence-based medicine dictates what therapies the clinician will offer in a given circumstance, ideally supported by (evidence-based) guidelines. While evidence-based medicine is a cornerstone of current medical practice, when taken alone it tends to decentralize the patient while ignoring the narrative from a more personal perspective. However, a newer narrative approach has the aim of combining evidence-based and narrative-based approaches, or "fact finding" with empathy, to create what could be considered as the "art of medicine" [4]. In this vision, medicine is not only caring for the patient's illness, but also how the illness is perceived, engaging the caregiver in real-life experiences. Thus, obtaining information about the patient through a narrative approach and routine clinical anamnesis cannot be considered to be comparable. There are different approaches to understanding the patient and what he or she is experiencing as a result of their illness. It is also important to understand that narration is communication, but narration, or communication can also be achieved through non-verbal channels that might include drawings, videos, paintings, and pictures to name a few. A simple drawing can be used to describe episodes of pain, for example, and watching a short video may be helpful for the patient to communicate feeling that they find difficulty in directly expressing. The idea that visual images can help to communicate pain has been previously highlighted by Padfield [5].

\section{Time constraints in a busy world}

Clinical practice that includes narration introduces a potential barrier to its inclusion in daily routines, namely, that clinicians, in today's time constraint environments constantly being pushed towards greater efficiency, do not have the time to dedicate to listen to patients. Physicians and other caregivers may feel that they risk being overwhelmed by patient complaints if they listen until the patient is finished. To counter such an argument, data from a previous study can be cited in which physicians were trained in active listening techniques, and were asked to not interrupt patients during the initial phase of the consultation [6]. In this context, mean spontaneous talking time was only $92 \mathrm{~s}$, and $78 \%$ of patients concluded their initial statement within 2 min. From that study, the authors concluded that "even in a busy practice driven by time constraints and financial pressure, 2 min of listening should be possible and will be sufficient for nearly $80 \%$ of patients". Considering this, all caregivers should reflect on the possibility to give patients greater freedom from time constraints during consultation, and encourage them to narrate their experiences.

\section{Recognizing the individual, not the patient}

As an example, narrative medicine can be recommended for better diagnosis of pain and its treatment (Fig. 2). Narrative medicine can complement more traditional evaluation techniques. In the case of pain, evaluation with VAS is commonly used to give the patient's pain a score that will drive treatment. Narrative evaluation, however, assesses the impact that the pain has on the patient's daily activities and quality of life. Together, both evaluation techniques can help the caregiver to remember that individuals are being treated, and not just
Fig. 1 Goals of narrative medicine
Narrative competence

Empathy

Reflection

Professionalism

Trustworthiness 
Fig. 2 Narrative medicine in diagnosis and treatment of pain

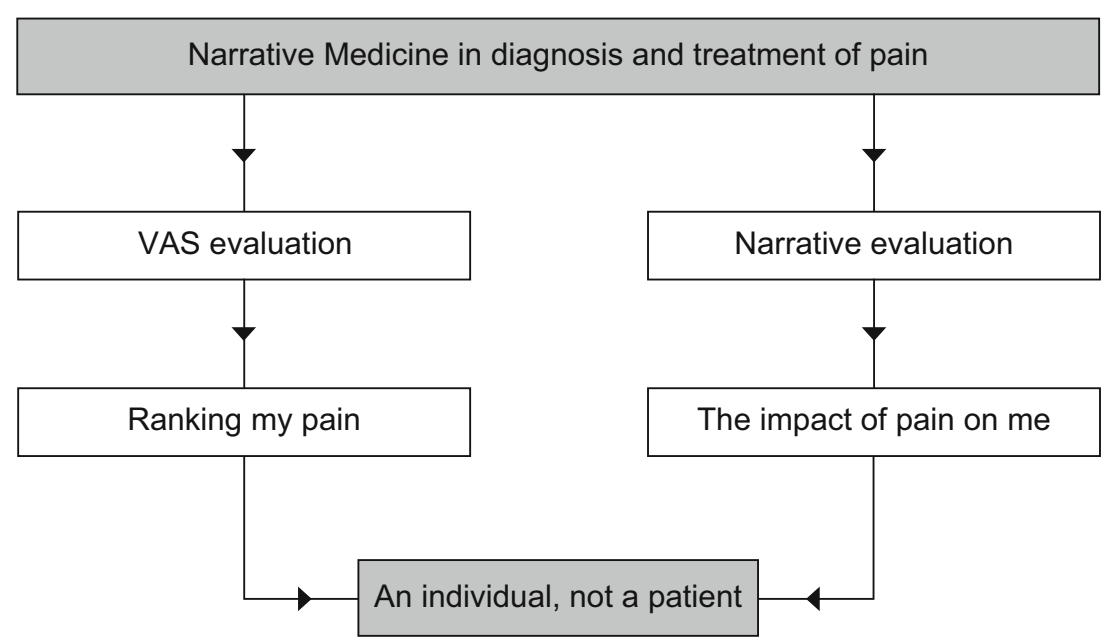

patients, each of whom have their own subjective problems related to their disease and its consequences. As an example, the impact of narrative medicine in cancer pain has been studied in a trial that randomized 234 patients to a narrative group (patients wrote a story about their pain), a questionnaire group (patients filled out the McGill Pain Questionnaire), and a control group (usual care) [7]. While pain intensity was similar between groups both before and after treatment, patients whose narratives had high emotional impact had significantly less pain than patients whose stories were less emotional. Indeed, both high- (such as questionnaires and assessment tools) and low-context approaches (such as story-telling) help to understand and share the experience of illness: both are important and both are necessary [8]. Referred to as narrative empathy, many believe that the process can aid in decision making and improve overall outcomes [8].

Narration is not an easy task as it can involve subjects that may not seem clinically relevant for the patient's care, giving precedence to the disease over the individual's overall wellbeing. This possibility was highlighted very well by the writer Souleika Jaouad, who was diagnosed with leukemia at the age of 22. In communicating about her experience with her treatment, she noted that "to my surprise, sex is not at the center of the conversation in the oncology unit - far from it" [9].
Furthermore, she said that the issues of sexuality and infertility had never been mentioned during her treatment. While caregivers may feel uncomfortable talking about such issues with their patients, they should also be aware that as individuals they may be confused and frustrated by the lack of communication about sensitive subjects.

\section{What narrative medicine is and is not}

There are many misconceptions about narrative medicine. Among these, it should not be considered as useful for only psychiatrists, psychologists, or palliative care physicians. Narrative medicine is also not something that should be applied only to patients needing end-of-life care, and should not be viewed with a negative attitude. It is, on the other hand, about listening to the patient about aspects that may not normally be expressed during a "routine" visit. It is also about providing greater empathy throughout the patient journey, during all aspects of diagnosis and treatment. As mentioned earlier, proper training in narrative medicine at an early stage may improve communication skills [3]. Narrative medicine, thus, is something for all caregivers. In order to achieve this, a strong frame of alliance is needed. Such a framework should
Fig. 3 Frame of alliance for narrative medicine

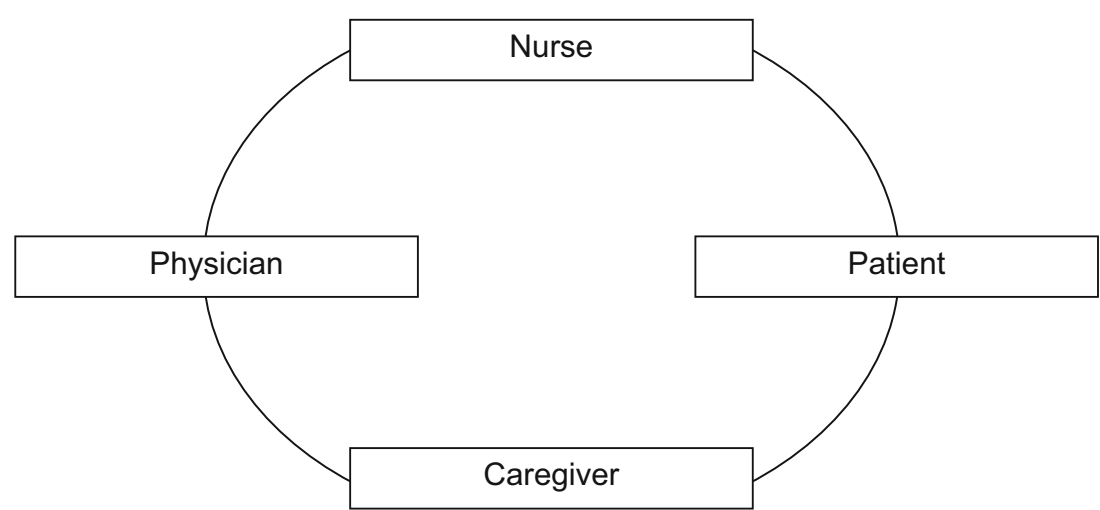


include not only the physician, but also nurses and other caregivers, working together with the patient (Fig. 3).

\section{Future perspectives for narrative medicine in daily practice}

Undoubtedly, medicine has made great strides in recent years in terms of the use of a number of new technologies. So-called e-health technologies will possibly allow building bridges as patients can be in closer contact with their healthcare providers. It is possible that new technologies could give clinicians more time for narrative techniques with patients. On the other hand, increased use of digital technologies could potentially reduce the opportunity for narrative contact, yet provide a starting point for discussion, such as with an electronically transmitted patient pain diary. Undoubtedly, the impact of new technologies will emerge once their use is more consolidated in the future. Nonetheless, "Even 'evidence-based' clinicians uphold the importance of clinical expertise and judgment" [10]. The clinician must also rely on patient narration to complement more objective clinical results. While on one hand, an evidence-based approach is needed, it should also be kept in mind that the art of medicine involves applying knowledge to a single individual. In the words of Rita Charon, "To listen to a story of illness is not a therapeutic act, but it gives dignity and honor to that voice". Clinical methods are not without their limitations that narrative medicine can help to overcome.

Acknowledgements I would like to thank all patients and families I met throughout my years as a Medical Oncologist.

\section{Compliance with ethical standards}

Funding None.

Conflict of interest The author received honoraria from Teva Pharmaceuticals Europe B. V for speaking at BeCOn OWN medical education event, supported by Teva Pharmaceuticals Europe B.V. Dr. Rosti declares that he has no conflict of interest.

Open Access This article is distributed under the terms of the Creative Commons Attribution-NonCommercial 4.0 International License (http:// creativecommons.org/licenses/by-nc/4.0/), which permits any noncommercial use, distribution, and reproduction in any medium, provided you give appropriate credit to the original author(s) and the source, provide a link to the Creative Commons license, and indicate if changes were made.

\section{References}

1. Charon R (2001) The patient-physician relationship. Narrative medicine: a model for empathy, reflection, profession, and trust. JAMA 286:1897-1902

2. Charon R (2007) What to do with stories: the sciences of narrative medicine. Can Fam Physician 53:1265-1267

3. Arntfield SL, Slesar K, Dickson J, Charon R (2013) Narrative medicine as a means of training medical students toward residency competencies. Patient Educ Couns 91:280-286

4. Charon R (2013) Narrative medicine: caring for the sick is a work of art. JAAPA $26: 8$

5. Padfield D (2011) "Representing" the pain of others. Health (London) 15:241-257

6. Langewitz W, Denz M, Keller A, Kiss A, Ruttimann S, Wossmer B (2002) Spontaneous talking time at start of consultation in outpatient clinic: cohort study. BMJ 325:682-683

7. Cepeda MS, Chapman CR, Miranda N, Sanchez R, Rodriguez CH, Restrepo AE et al (2008) Emotional disclosure through patient narrative may improve pain and well-being: results of a randomized controlled trial in patients with cancer pain. J Pain Symptom Manag 35:623-631

8. Moore RJ, Hallenbeck J (2010) Narrative empathy and how dealing with stories helps: creating a space for empathy in culturally diverse care settings. J Pain Symptom Manag 40:471-476

9. New York Times Available at: https://wellblogsnytimescom/2013 /02/14/life-interrupted-crazy-unsexy-cancer-tips

10. Greenhalgh T (1999) Narrative based medicine: narrative based medicine in an evidence based world. BMJ 318:323-325 